\title{
TECHNICAL AND ECONOMIC FEASIBILITY OF IMPROVED POSTHARVEST MANAGEMENT PRACTICES IN ENHANCING THE EGGPLANT VALUE CHAIN OF BANGLADESH
}

\author{
M.A. Rahman' ${ }^{*}$, M. Islam², M.M. Begum³ and S. Arfin' ${ }^{1}$ \\ Received 22 August 2019, Revised 30 November 2019, Accepted 24 December 2019, Published online 31 December 2019
}

\begin{abstract}
A study was carried out to evaluate the suitability and effectiveness of improved postharvest management practices (IPMP) in enhancing the eggplant (Solanum melongena L.) value chain of Bangladesh. In IPMP, sorting, grading and washing of eggplants were done, and packed them in plastic crates with or without modified atmosphere packaging (MAP). Traditional postharvest management practices (TPMP) existed in the value chain was used as control treatment. IPMP including the use of plastic crate with MAP reduced weight losses by 26.7 and $38.0 \%$ at wholesale and 2-days display at retail outlets. The total postharvest loss of eggplant handled with TPMP including packed in jute sack was 40.0\%, whereas it was only $4.5 \%$ when followed IPMP. The reduction of postharvest losses of eggplants handled with IPMP amounted to $88.7 \%$, and $100.0 \%$ fruit could be sold at retail outlets. The additional weekly gross income of a small trader by selling $1000 \mathrm{~kg}$ eggplant handled with IPMP comprising the plastic crates with MA packaging would be BDT 17,190 (USD 207).
\end{abstract}

Keywords: Eggplant, Postharvest Management, Loss Reduction, Packaging, Value Chain, Economic Benefit, Bangladesh.

\footnotetext{
${ }^{1}$ Postharvest Technology Section, Horticulture Research Centre, BARI, Joydebpur, Gazipur-1701, Bangladesh.

${ }^{2}$ Regional Agricultural Research Station, BARI, Jessore, Bangladesh.

${ }^{3}$ Tuber Crop Research Centre, BARI, Joydebpur, Gazipur-1701, Bangladesh.

*Corresponding author's email: dratiqbari@gmail.com (M.A. Rahman)
}

Cite this article as: Rahman, M.A., Islam, M., Begum, M.M. and Arfin, S. 2019. Technical and economic feasibility of improved postharvest management practices in enhancing the eggplant value chain of Bangladesh. Int. J. Agril. Res. Innov. Tech. 9(2): 35-41. DOI: 10.3329/ijarit.v9i2.45408.

\section{Introduction}

Eggplant (Solanum melongena L.) is one of the most important and popular vegetable crops grown commercially round the year in Bangladesh (Quamruzzaman et al., 2009). A total of 507,432 metric tons of eggplant was produced from 50,955.50 ha land in Bangladesh in 2017 (BBS, 2018). It contains important nutrient components with functional properties like biologically essential minerals, ascorbic acid, soluble phenols (Nino-Medina et al., 2014), potassium, calcium, sodium and iron (Mohamed et al., 2003; Raigon et al., 2008) as well as dietary fibre (USDA, 2014; Nino-Medina et al., 2014; Sanchez-Castillo et al., 1999).

Eggplant is a perishable crop having short postharvest life. In Bangladesh, the postharvest loss of eggplant was estimated at $29.4 \%$ from harvesting to consumption (Hassan, 2010), which mainly attributed to improper postharvest management practices. In traditional postharvest management practices (TPMP), generally farmers and traders do not carry out sorting, grading or washing for marketing eggplant. At local assembling market, the traders purchase eggplants from farmers, and directly pack into jute sacks having 100 to $800 \mathrm{~kg}$ capacity for sending them to the distant wholesale markets. These heavy packages are roughly handled during loading, unloading and subsequent handling, which result in bruising, cracking and compression damage of the crop. Due to getting mechanical damage, eggplants become more susceptible to microorganisms causing decay and also suffer from nutritional loss at the retail outlets. At the end, the consumers get poor quality and unsafe eggplants from the retailers.

The technical and economic effectiveness of improved postharvest technologies can be established by testing them under actual value chain system. In this regard, a study was needed to carry out to compare the effectiveness between traditional and improved postharvest management practices (IPMP) in the eggplant value chain. Improved postharvest management 
practices such as, harvesting at optimum maturity stage, use of plastic bucket as harvesting container, sorting, grading, washing with clean potable water, use of plastic crates as packaging container, and careful loading and unloading during transportation etc. were followed as interventions in the value chain in reducing postharvest losses and managing quality and safety of the crop.

Packaging provides protection of produces from dust and reduces microbial contamination from surroundings. Thus, proper packaging is essential in maintaining product quality during transport and subsequent handling (Esguerra et al., 2016). Consumer demand for produce that is safe and of high quality has been a major driver of the shift from using traditional bulk packaging materials to the use of improved containers such as reusable plastic crates (Rapusas and Rolle, 2009). On the other hand, packaging of fresh fruits and vegetables in plastic films restrict the transmission of respiratory gases for the accumulation of carbon dioxide and depletion of oxygen around the crop, which may increase their shelf life (Kader et al., 1989). Eggplant in perforated polyethylene bag prolonged shelf life maintaining fruit quality compared to unpacked fruit (Nasrin et al., 2008).

Therefore, the experiment was undertaken to determine the suitability and effectiveness of IPMP in enhancing eggplant value chains. The findings of this study will provide valuable information on the impact of IPMP of eggplant that will serve as the basis in the formulation of interventions in the value chain towards quality maintenance and loss reduction.

\section{Materials and Methods}

\section{Materials and experimental procedures}

The experiment was conducted with eggplants cv. 'Chaga'. Eggplants were collected directly from the farmers from a local assemble market of Jessore and divided into two lots; one for existing practices followed by the traders in a simulated marketing chain and another following improved postharvest management practices. For traditional postharvest management practices (TPMP), sorting, grading and washing were not done. Eggplants were directly packed in jute sacks of $100 \mathrm{~kg}$ capacity and sealed with nylon string. On the other hand, improved postharvest practices including sorting, grading and washing with clean potable water were done in improved postharvest management practices (IPMP), and packed in 20 kg capacity stackable plastic creates with or without modified atmosphere packaging (MAP). Polyethylene of $30 \mu$ thickness with $1 \%$ perforation was used as MAP. The eggplants were then loaded in a 12-ton truck together with other commercial loaded vegetables and started to transport in the evening (6:00 pm) of the same day and reached Vogra wholesale market at
Gazipur about 8:00 pm of the following day. Distance from Jessore to Gazipur is $250 \mathrm{~km}$. After collecting the necessary data at wholesale market, the produces were brought to the postharvest laboratory of Horticulture Research Centre of BARI using a pick up van. The eggplants were evaluated at the laboratory, where a thorough evaluation of the recovery of good quality (sound), mechanically damaged and unmarketable fruits from the top, middle and bottom portions of the three types of containers. After evaluation, 50 sample eggplants were randomly taken from the top, middle and bottom portions of each container, were placed in separate plastic crates and distributed to three retail outlets of Gazipur wet vegetable market. Another 50 eggplants were randomly taken from different portions of each container were left in the laboratory also for daily evaluation. Both in the TPMP and IPMP, there were three plastic crates with each crate having 50 eggplants that was considered as a replication. Each eggplant in a crate was evaluated daily during the 2-day retail period under ambient condition $\left(25^{-28^{\circ} \mathrm{C}}\right.$, 80$85 \% \mathrm{RH})$.

\section{Data recording}

Data were collected every day on weight loss, mechanical damage and decay caused by pathogens. Eggplants were evaluated individually as to the severity of mechanical damage as follows: 1-sound (no damage), 2-slight, 3moderate, and 4-severe. Fruits with evident compression damage and bruising/abrasion were classified as moderately damaged, and those with cracks as severely damaged were considered unmarketable. The change in the external appearance of the eggplant, which affects marketability was also monitored daily during the 2-day retail period. The collected data were analyzed to calculate the loss in the whole supply chain.

\section{Experimental design and statistical analysis}

The experiment was carried out in a randomized complete design (RCD) with three replications. The collected data were subjected to analysis of variance (ANOVA) using ' $R$ ' Statistical Software version 3.1.2. The results showing significant differences were then subjected to mean separation using LSD test at $\mathrm{P}<0.05$.

\section{Results and Discussion}

\section{Weight loss}

Weight loss of eggplant occurred mainly due to transpiration during transportation and displaying for sale at retail outlets. Loss during transportation was recorded of $1.1-1.9 \%$ at the wholesale market, showing the highest loss in fruits packed in PC without MAP, which was not significantly $(P<0.05)$ different with jute sack (Table 1). 
Table 1. Weight loss (quantitative loss) of eggplant at wholesale market and retail outlets.

\begin{tabular}{|l|c|c|c|}
\hline Treatment & $\begin{array}{c}\text { At wholesale } \\
\text { market }\end{array}$ & $\begin{array}{c}\text { Cumulative weight loss (\%) } \\
\text { Day } 1 \text { at retail } \\
\text { outlet }\end{array}$ & Day 2 at retail outlet \\
\hline IPMP + PC with MAP & $1.1 \mathrm{~b}$ & $2.34 \mathrm{~b}$ & $4.50 \mathrm{~b}$ \\
\hline IPMP + PC without MAP & $1.9 \mathrm{a}$ & $4.62 \mathrm{a}$ & $7.31 \mathrm{a}$ \\
\hline TPMP + Jute sack & $1.5 \mathrm{ab}$ & $4.44 \mathrm{a}$ & $7.28 \mathrm{a}$ \\
\hline Level of significance (\%) & 0.05 & 0.05 & 0.05 \\
\hline
\end{tabular}

Values in each column followed by the same letter (s) are not differed significantly.

IPMP = Improved postharvest management practices.

$T P M P=$ Traditional postharvest management practices .

$P C=$ Plastic crate; $M A P=$ Modified atmosphere packaging (1\% perforated).

Similarly, the maximum weight loss of $4.6 \%$ occurred on day 1 at retail outlets for open PC, which increased up to $7.3 \%$ on day 2 and was statistically similar with eggplant in jute sack. On the other hand, the eggplants handled with IPMP comprising packed in PC with MAP showed consistently lowest weight loss at each stages of value chain, exhibiting $4.5 \%$ on day 2 at retail outlets. Thus, at the end of 2-day retail period, the cumulative weight losses of eggplants were recorded by $4.5,7.3$ and $7.2 \%$ for PC with MAP, PC without MAP and TPMP with jute sack, respectively. Findings of this study showed the efficacy of MA packaging of eggplant in reducing the weight loss compared to other packaging containers. Results of this experiment are in agreement with Nasrin et al. (2008) who reported that eggplants lost maximum weight of 13.3\% when kept in unpackaged condition whereas, it was only $3 \%$ when kept them in $1 \%$ perforated polyethylene bag on day 6 of storage at ambient condition. No significant difference was observed between eggplants packed in PC without MAP and jute sack regarding weight loss of eggplant at retail shop.

\section{Recovery of good quality (sound) fruits at wholesale level}

Table 2 shows the recovery of sound (no damage) and mechanically-damaged eggplant upon arrival to the wholesale market. Eggplants packed in plastic crates had significantly $(P \leq 0.05)$ higher recovery of sound fruits than those packed in jute sacks. Average recovery of sound eggplants was found about $97.0 \%$, which handled with IPMP and packed in PC with or without MAP. On the other hand, it was $33.3 \%$ when handled with TPMP.

Table 2. Proportion of sound and mechanically damaged eggplant at wholesale market.

\begin{tabular}{|l|c|c|c|c|}
\hline Treatment & Sound eggplant (\%) & \multicolumn{3}{c|}{ Mechanically damaged eggplant (\%) } \\
\hline IPMP + PC with MAP & & Bruising & Compression & Cracks \\
\hline IPMP + PC without MAP & $97.0 \mathrm{a}$ & 0.0 & $0.0 \mathrm{~b}$ & $0.0 \mathrm{~b}$ \\
\hline TPMP + Jute sack & $97.6 \mathrm{a}$ & 0.0 & $0.0 \mathrm{~b}$ & $0.0 \mathrm{~b}$ \\
\hline Level of significance (\%) & $33.3 \mathrm{~b}$ & 0.0 & $57.5 \mathrm{a}$ & $9.2 \mathrm{a}$ \\
\hline
\end{tabular}

Values in each column followed by the same letter (s) are not differed significantly.

$I P M P=$ Improved postharvest management practices.

$T P M P=$ Traditional postharvest management practices.

$P C=$ Plastic crate; $M A P=$ Modified atmosphere packaging ( $1 \%$ perforated).

At wholesale level, the incidence of mechanical damage in eggplants in the form of compression and crack was found $57.5 \%$ and $9.2 \%$, respectively when packed in the jute sacks. On the other hand, no incidence of mechanical damage was found in eggplants that packed PC with or without MAP at wholesale level (Table 2). Plastic crates are rigid and highly recommended as packaging containers for tomato and other fresh vegetables since they provide adequate protection against compression damage (Esguerra et al., 2016; Rapusas and Rolle, 2009).

\section{Recovery of sound eggplants at the retail outlets during two days of shelf period}

By integrating IPMP comprising the stackable plastic crates as packaging container along with and without MAP, the recovery of sound and highly marketable eggplants amounted to 88.6 and $86.6 \%$, respectively on day 1 (Table 3 ), which decreased slightly on day 2, reaching 87.3 and $62.6 \%$, respectively. In contrast, the recovery of sound eggplants which handled with TPMP and packed in jute sacks was 24.4 and $22.6 \%$ on day 1 and day 2, respectively, which was significantly $(P<0.05)$ lower than IPMP. Among three packaging type, plastic crate with MAP showed significantly $(P \leq 0.05)$ the highest recovery of sound eggplant during 2-day retail display which was followed by plastic crate without MAP. 
Table 3. Proportion of sound eggplant during 2-days retail outlets.

\begin{tabular}{|l|c|c|}
\hline Packaging type & \multicolumn{2}{c|}{ Sound eggplant at retail outlets (\%) } \\
\hline IPMP + PC with MAP & Day 1 & Day 2 \\
\hline IPMP + PC without MAP & $88.6 \mathrm{a}$ & $87.3 \mathrm{a}$ \\
\hline TPMP + Jute sack & $86.6 \mathrm{a}$ & $62.6 \mathrm{~b}$ \\
\hline Level of significance (\%) & $24.4 \mathrm{~b}$ & $22.6 \mathrm{c}$ \\
\hline
\end{tabular}

Values in each column followed by the same letter (s) are not differed significantly.

$I P M P=$ Improved postharvest management practices.

$T P M P=$ Traditional postharvest management practices.

$P C=$ Plastic crate $; M A P=$ Modified atmosphere packaging (1\% perforated).

\section{Incidence of mechanically damaged eggplants at retail outlets}

All forms of mechanical damages including bruising, compression and cracking were apparent in eggplants, which handled with TPMP and packed in jute sacks. On day 1 at retail outlet, significantly $(P \leq 0.05)$ the highest incidence of mechanical-damage amounted to $53.8 \%$ was recorded in eggplants handled with TPMP that caused by bruising and/or compression effect during transportation and subsequent handling (Table 4). The incidence of mechanical damage in traditionally handled eggplants sharply increased over night, reaching $61.7 \%$ on day 2 at retail outlets. On the other hand, significantly $(P<0.05)$ the lowest mechanically damaged eggplants were found in IPMP eggplants that packed in PC with MAP showing 11.3 and $12.6 \%$ on days 1 and day 2, respectively. Packaging of eggplants in PC with MAP reduced the mechanical damage by $79.4 \%$ over the jute sack packaging. Results of another handling trial of eggplant also showed a reduction of compression damage from 52.7 to $32.0 \%$ and 37.4 to $23.3 \%$ for "Casino" and "Black Ninja" varieties, respectively when transported in plastic crates (PHTRC, 2004).

Table 4. Mechanically damaged eggplant (compressed + bruised) during 2-days retail display.

\begin{tabular}{|l|c|c|}
\hline Treatment & Mechanically damaged egglant at retail outlets (\%) \\
\hline IPMP + PC with MAP & Day 1 & Day 2 \\
\hline IPMP + PC without MAP & $11.3 \mathrm{~b}$ & $12.6 \mathrm{c}$ \\
\hline TPMP + Jute sack & $13.3 \mathrm{~b}$ & $30.6 \mathrm{~b}$ \\
\hline Level of significance (\%) & $53.8 \mathrm{a}$ & $61.7 \mathrm{a}$ \\
\hline
\end{tabular}

Values in each column followed by the same letter (s) are not differed significantly.

$I P M P=$ Improved postharvest management practices.

$T P M P=$ Traditional postharvest management practices.

$P C=$ Plastic crate; $M A P=$ Modified atmosphere packaging (1\% perforated).

\section{Recovery of marketable eggplants at retail outlets}

During 2-day retail display, the proportion of total marketable eggplants handled with IPMP and packed in PC with MAP remained $100 \%$ on day 1 and day 2 (Table 5). However, it decreased slightly on day 2 when PC without MAP was used as packaging container. In contrast, eggplants handled with TPMP and packed in jute sack exhibited significantly $(P \leq 0.05)$ the lowest proportion of marketable fruits compared to those IPMP. The recovery of marketable eggplants followed TPMP and packed in jute sack was $86.2 \%$ on day 1 , which decreased rapidly, reaching $76.5 \%$ on day 2 at retail outlets. Total marketable fruits consisted of sound eggplants and fruit exhibiting slight compression and abrasion. The incidence of slightly compressed eggplant was also higher in jute sacks compared to those eggplants, which packed in PC.

Table 5. Total marketable eggplant at retail outlets.

\begin{tabular}{|l|c|c|}
\hline Packaging type & Total marketable eggplant at retail outlets (\%) \\
\hline IPMP + PC with MAP & Day 1 & Day 2 \\
\hline IPMP + PC without MAP & $100 \mathrm{a}(11.3)$ & $100 \mathrm{a}(12.6)$ \\
\hline TPMP + Jute sack & $100 \mathrm{a}(13.3)$ & $93.3 \mathrm{a} \mathrm{(30.6)}$ \\
\hline Level of significance (\%) & $86.2 \mathrm{~b}(53.8)$ & $76.5 \mathrm{~b}(61.7)$ \\
\hline
\end{tabular}

Values in each column followed by the same letter (s) are not differed significantly.

$I P M P=$ Improved postharvest management practices.

$T P M P=$ Traditional postharvest management practices

$P C=$ Plastic crate $; M A P=$ Modified atmosphere packaging ( $1 \%$ perforated).

Figures in the parenthesis are the mechanically damaged but marketable eggplant (\%). 
Postharvest losses of eggplant in the vahue chain

Figure 1 shows the proportion of postharvest losses of eggplants at each stages of value chain. At wholesale level, there was no unmarketable eggplants, which handled with IPMP and packed in plastic crates with or without MAP. In contrast,
9.2\% eggplants found crack when they were handled with TPMP and packed in jute sack. Weight loss is considered as quantitative loss, which found higher (7.3\%) both in open plastic crate and jute sack.

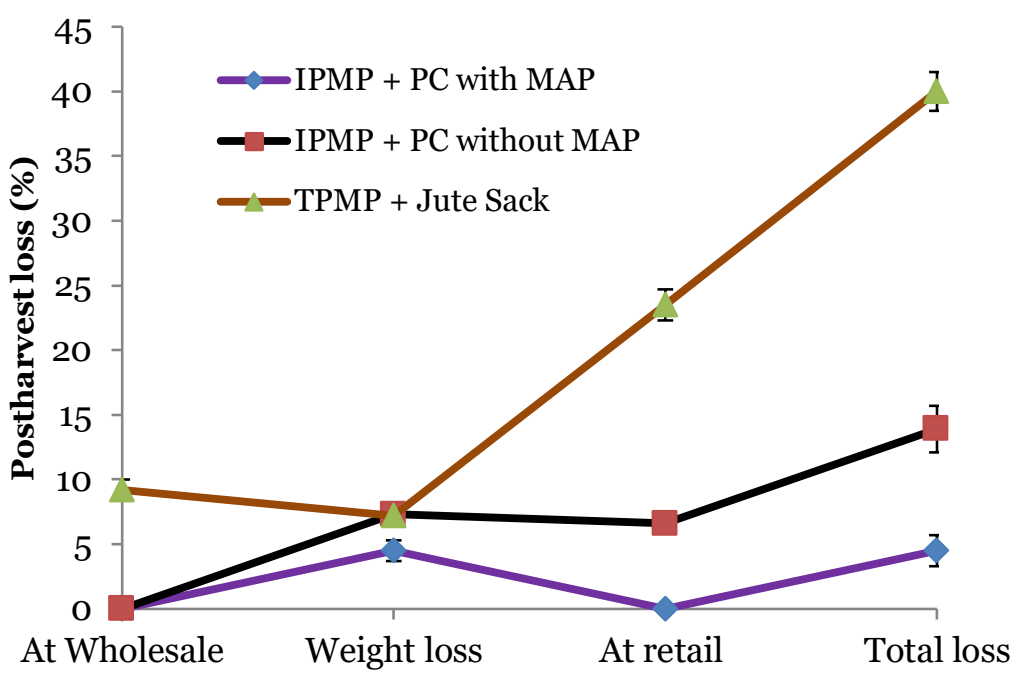

Egg plant value chain stages

Fig. 1. Efficacy of postharvest management practices along with different packaging containers in reducing postharvest losses of eggplant at different stages of value chain. Vertical bars represent the standard deviation.

On the other hand, significantly $(P<0.05)$ lowest weight loss of $4.5 \%$ was recorded in eggplants packed in plastic crates with MA packaging. At retail level, the maximum postharvest loss amounting $23.5 \%$ was recorded in eggplants that handled with TPMP, which followed by IPMP and packed in plastic crates without MAP, showing 6.6\% loss. In contrast, there was no quantitative loss of eggplant except transpiration loss when packed in plastic crate with MA packaging. The reason of the inhibition of postharvest loss in eggplants packed in plastic crates with MAP might be due to the low level of $\mathrm{O}_{2}$ and elevated $\mathrm{CO}_{2}$ concentrations in MA packaging that can significantly reduce the rates of senescence primarily by reducing the synthesis and perception of ethylene (Abeles et al., 1992). At the retail level, the reduction in postharvest losses amounted to $100.0 \%$ and $93.4 \%$ with the use of IPMP comprising packed in plastic crates with and without MAP, respectively.

Absence of postharvest treatment, poor packaging, rough handling during transportation, lack of storage facilities and low farm gate price are the major causes of postharvest losses of eggplant (Kaysar et al., 2016). Similarly, in this study the cumulative postharvest losses of eggplant in the entire value chain was calculated showing the highest loss 40.0\% (weight loss $7.2+$ cracks at wholesale $9.2+$ mechanical damage at retail $23.5 \%$ ) when handled with TPMP including packed in jute sacks. The lowest loss on the other hand, was recorded $4.5 \%$ in eggplants, which packed in plastic crate with MAP during transportation, subsequent handling and marketing under IPMP (Fig. 1). Thus, the postharvest losses of eggplant could be reduced by $88.7 \%$ by following the IPMP including use of plastic crates with MAP as a packaging container instead of jute sack. Findings of this study are in agreement with Fernando (2006) who reported that the introduction of plastic crates as packaging container in the supply chain reduced postharvest losses of vegetables from 30\% to $5 \%$ during handling and marketing. It was also reported that the use of plastic crates for handling and transportation of fruits such as mangoes and avocados, resulted in a reduction of losses from $30 \%$ to $6 \%$ (Fernando, 2006). Use of plastic crate with MA packaging during transportation and marketing of eggplants reduced the respiration and transpiration rate, which might result the lowest postharvest loss compared to other packaging system (Kader et al., 1989).

\section{Partial budget analysis for estimating profitability of using plastic crate as packaging container}

A simple profitability tool such as partial budget analysis was used to analyze the expected changes in returns because of postharvest technology intervention like the use of plastic crates. Assuming that one trader can be handled $1000 \mathrm{~kg}$ of eggplant per week and that the eggplants are packed in jute sacks during transportation from Jessore to Gazipur wholesale market by a commercial truck. From the results of the present 
study, the loss of eggplant due to mechanical damage amounted to $32.7 \%$, which is equivalent to $327 \mathrm{~kg}$ of eggplant per week (Table 6). Partially mechanical damaged eggplant, on the other hand was $447 \mathrm{~kg}$, which can be sold at lower price (BDT $\left.30 \mathrm{~kg}^{-1}\right)$. In contrast, the use of plastic crates with
MAP as packaging container, there was no mechanical damage. However, $126 \mathrm{~kg}$ (12.6\%) eggplant was found partially damage but marketable and thus, the complete loss of eggplant was only $45 \mathrm{~kg}$ due to transpiration.

Table 6. Effect of packaging containers in reducing postharvest loss of eggplants during transportation and subsequent handling.

\begin{tabular}{|l|c|c|c|c|c|c|c|}
\hline & \multicolumn{3}{c}{ Sound eggplant } & \multicolumn{3}{c}{ Compressed/ } & \multicolumn{2}{c|}{$\begin{array}{c}\text { Unmarketable } \\
\text { eggplant }\end{array}$} & $\begin{array}{c}\text { Total } \\
\text { Price }\end{array}$ \\
\cline { 2 - 8 } & $\begin{array}{c}\text { Amount } \\
(\mathrm{kg})\end{array}$ & $\begin{array}{c}\text { Price } \\
(\mathrm{BDT})\end{array}$ & $\begin{array}{c}\text { Amount } \\
(\mathrm{kg})\end{array}$ & $\begin{array}{c}\text { Price } \\
(\mathrm{BDT})\end{array}$ & $\begin{array}{c}\text { Amount } \\
(\mathrm{kg})\end{array}$ & $\begin{array}{c}\text { Price } \\
(\mathrm{BDT})\end{array}$ & \\
\hline PC with MAP & 873 & 34920 & 126 & 3780 & 45 & 0.0 & $\begin{array}{c}38700 \\
(96.7 \%)\end{array}$ \\
\hline PC without MAP & 625 & 25000 & 240 & 7200 & 66 & 0.0 & $\begin{array}{c}32200 \\
(80.5 \%)\end{array}$ \\
\hline Jute Sack & 226 & 9040 & 447 & 13410 & 327 & 0.0 & $\begin{array}{c}22450 \\
(56.1 \%)\end{array}$ \\
\hline
\end{tabular}

NB: Retail market price: Good quality eggplant $=B D T 40 \mathrm{~kg}^{-1}$; partially damaged eggplant $=B D T 30 \mathrm{~kg}^{-1}$. $B D T=$ Bangladeshi taka; $P C=$ Plastic crate; $M A P=$ Modified atmosphere packaging (1\% perforated); Figures in the parenthesis indicate the percentage recovery of total price.

Added returns: The retail prices of good quality and partially damaged eggplants were estimated to BDT 40 and $30 \mathrm{~kg}^{-1}$, respectively. Thus, the estimated gross income with the use of jute sack would be 22,450. With the use of plastic crates, the loss was $45 \mathrm{~kg}$, hence the estimated gross income would be BDT 38700 . Therefore, the additional gross income per week as a result of using plastic crate would amounted to BDT $(38700-22450)=$ BDT $1,6250($ Table 6$)$.

Added cost: Use of plastic crates entails depreciation cost of plastic crates and opportunity cost of capital invested in purchasing plastic crates. For $1,000 \mathrm{~kg}$ of eggplants, 50 plastic crates are needed which cost BDT 16,000 @ BDT 320 crate $^{-1}$. Plastic crates normally last for 10 years. So the depreciation cost is BDT 1600 year $^{-1}$ or BDT 30.76 week $^{-1}$ at $10 \%$ depreciation cost. Salvage value is o. The opportunity cost of capital is based on the assumption that the interest rate is $10 \%$ and is computed as follows:

$$
I=\frac{(16,000+(16,000-1600)}{2.0}
$$

$=$ BDT 1520 year $^{-1}$ or 29.23 week $^{-1}$

The reduced cost in terms of labour for sorting eggplants due to mechanical damage with the use of jute sack was BDT 1000 (2 man-day week ${ }^{-1}$ at BDT 500 day $\left.^{-1}\right)$. With an additional gross income of BDT 16,250 week $^{-1}$ plus reduced labour cost of BDT 1000 week $^{-1}$, one small trader who uses plastic crate will gain an additional weekly income of BDT 17,250 as shown in Table 7.

Table 7. Partial budget analysis for testing the profitability of using plastic crates for eggplant (with $100 \%$ reduction in loss at wholesale level).

\begin{tabular}{|c|c|c|c|}
\hline Total gain (BDT) & & Total loss (BDT) & \\
\hline Added income: & & Added cost: & \\
\hline \multirow[t]{2}{*}{ Additional gross income } & $16,250.00$ & Depreciation & 30.76 \\
\hline & & Opportunity cost of capital & 29.23 \\
\hline \multicolumn{4}{|l|}{ Reduced cost } \\
\hline Savings in labour for sorting & 1000.00 & & \\
\hline Total A & $17,250.00$ & Total B & 60.00 \\
\hline
\end{tabular}

\section{Conclusion}

Findings of the present study revealed that the main causes of postharvest loss amounting to $40 \%$ were due to weight loss, fruit cracks and compression damage obtained in the jute sacks when followed TPMP. The integration of IPMP including the use of stackable plastic crates with MA packaging was more profitable that resulted in $88.7 \%$ reduction in loss by preventing the transpiration and mechanical damage, and 100\% 
eggplants could be sold at retail outlets. Thus, the existing value chain system of eggplant in Bangladesh could be improved by intervening of improved postharvest management practices including sorting, grading, washing and use of stackable plastic crates as packaging container in order to reduce high postharvest loss and retain produce quality, its marketability and profitability.

\section{References}

Abeles, F.B, Morgan, P.W. and Saltveit, M.E. 1992. Ethylene in plant biology. $2^{\text {nd }}$ ed. San Diego, Academic Press. 414p.

BBS. 2018. Yearbook of Agricultural Statistics. Bangladesh Bureau of Statistics, Ministry of Planning, Government of the People's Republic of Bangladesh. 391p.

Esguerra, E.B., Rolle, R. and Rahman, M.A. 2016. Postharvest Management of Tomato for Quality and Safety Assurance, Extension Brochure. FAO Regional Office for Asia and the Pacific. 44p.

Fernando, M.D. 2006. Country paper-Sri Lanka (2). pp. 264-275. In: Proceedings of the seminar on post-harvest management of fruit and vegetables in the Asia-Pacific region. Asian Productivity Organization (Tokyo) and Food and Agriculture Organization (Rome).

Hassan, M.K. 2010. Postharvest Loss Assessment: A Study to Formulate Policy for Loss Reduction of Fruits and Vegetables and Socio-Economic Uplift of the Stakeholders. Final Report of USAID and EC funded project under national food policy capacity strengthening programme, Food and Agriculture Organization of the United Nations and Food Planning and Monitoring Unit, Ministry of Food and Disaster Management, Bangladesh, 188p. http://fpmu.gov.bd/agridrupal/sites/default /files/Kamrul Hassan-PR8-o8.pdf

Kader, A.A., Zagory, D. and Kerbel, E.L. 1989. Modified atmosphere packaging of fruits and vegetables. Crit. Rev. Food Sci. 28(1): 1-30. DOI: $10.1080 / 10408398909527506$.

Kaysar, M.I., Mia, M.S., Islam, M.S. and Kausar, A.K.M.G. 2016. Postharvest loss assessment of brinjal in some selected areas of Bangladesh. Int. J. Bus. Manag. Soc. Res. 2(2): 118-124.
Mohamed, A.E., Rashed, M.N. and Mofty, A. 2003. Assessment of essential and toxic elements in some kinds of vegetables. Ecotoxicol. Environ. Safe. 55(3): 251-260. DOI: 10.1016/So147-6513(03)00026-5.

Nasrin, T.A.A., Molla, M M., Islam, M.N. Matin, M.A. and Bhuyan, M.A.J. 2008. Effect of chlorine wash and packaging technique on shelf life and quality of eggplant. $J$. Argil. Engin. IEB. 35/AE: 33-37.

Nino-Medina, G., Muy-Rangel, D., Gardea-Bejar, A., Gonzalez-Aguilar, G., Heredia, B., BaezSanudo, M., Siller-Cepeda, J. and Velez De La Rocha, R. 2014. Nutritional and nutraceutical components of commercial eggplant types grown in Sinaloa, Mexico. Not. Bot. Hort. Agrobot. Clujna. 42(2): 538544. DOI: $10.1583 /$ nbha4229573.

PHTRC Report. 2004. Post-harvest systems improvement and quality assurance for tomato. PHTRC, College of Agriculture, University of the Philippines Los Banos, Laguna. 2op.

Quamruzzaman, A.K.M., Chawdhury, M.J., Akhter, L., Rashid, M.A. and Ahmad, S. 2009. Genetic divergence study in eggplant (Solanum melongena L.). Bangladesh $J$. Agric. 34(1): 87-92.

Raigon, M.D., Prohens, J., Munoz-Falcon, J.E. and Nuez, F. 2008. Comparison of eggplant landraces and commercial varieties for fruit content of phenolics, minerals, dry matter and protein. J. Food Compos. Anal. 21(5): 370-376.

Rapusas, R.S. and Rolle, R.S. 2009. Management of reusable plastic crates in fresh produce supply chains-a technical guide. FAO Regional Office for Asia and the Pacific, Thailand, 42p.

Sanchez-Castillo, C.P., Englyst, H.N., Hudson, G.J., Lara, J.J., Solano, M.L., Munguia, J.L. and James, W.P. 1999. The non-starch polysaccharide content of Mexican foods. J. Food Compos. Anal. 12(4): 293-314.

USDA (United States Department of Agriculture). 2014. USDA National Nutrient Database for Standard Reference. http://www.nal.usda.gov/fnic/foodcomp/se arch. 